\title{
Phosphate to Creatinine Ratio Measurement
}

National Cancer Institute

\section{Source}

National Cancer Institute. Phosphate to Creatinine Ratio Measurement. NCI Thesaurus. Code C79461.

The determination of the ratio of phosphate compared to creatinine present in a sample. The measurement may be expressed as a ratio or percentage. 